TITLE:

\title{
Heat transfer characteristics of a planar water jet impinging normally or obliquely on a flat surface at relatively low Reynolds numbers
}

\section{$\operatorname{AUTHOR}(\mathrm{S}):$}

Ibuki, Kazuya; Umeda, Taichi; Fujimoto, Hitoshi; Takuda, Hirohiko

\section{CITATION:}

Ibuki, Kazuya ...[et al]. Heat transfer characteristics of a planar water jet impinging normally or obliquely on a flat surface at relatively low Reynolds numbers. Experimental Thermal and Fluid Science 2009, 33(8): 1226-1234

\section{ISSUE DATE:}

2009-11

URL:

http://hdl.handle.net/2433/237633

\section{RIGHT:}

(c) 2009. This manuscript version is made available under the CC-BY-NC-ND 4.0 license

http://creativecommons.org/licenses/by-nc-nd/4.0/:; The full-text file will be made open to the public on 1 November 2011 in accordance with publisher's 'Terms and Conditions for Self-Archiving'; この論文は出版社版でありません。引用 の際には出版社版をご確認ご利用ください。; This is not the published version. Please cite only the published version. 


\title{
Heat Transfer Characteristics of a Planar Water Jet Impinging Normally or Obliquely on a Flat Surface at Relatively Low Reynolds Numbers
}

\author{
Kazuya Ibuki $^{1}$, Taichi Umeda ${ }^{2}$, Hitoshi Fujimoto ${ }^{3}$, Hirohiko Takuda ${ }^{3}$ \\ 1. Graduate Student at Kyoto University, Kyoto 606-8501, Japan, \\ Presently, JFE steel corporation. \\ 2. Graduate Student at Kyoto University, Kyoto 606-8501, Japan \\ Presently, Panasonic corporation. \\ 3. Graduate School of Energy Science, Kyoto University, Kyoto 606-8501, Japan
}

\begin{abstract}
The heat transfer characteristics of a planar free water jet normally or obliquely impinging onto a flat substrate were investigated experimentally. The planar jet issued from a rectangular slot nozzle with a cross section of $1.62 \mathrm{~mm}$ x $40 \mathrm{~mm}$. The mean velocity at the nozzle exit ranged from 1.5 to $6.1 \mathrm{~m} / \mathrm{s}$. The corresponding Reynolds number range based on the nozzle gap and the mean velocity was 2,200 to 8,800 . Constant heat flux conditions were employed at the solid surface. Various impingement angles between the vertical planar jet and the inclined solid surface were investigated: $90^{\circ}$ (normal collision), $70^{\circ}, 60^{\circ}$, and $50^{\circ}$. In the case of normal collisions, the Nusselt number is high at the impingement line, and decreases with departures from it. The stagnation Nusselt numbers were compared to the predictions of several correlations proposed by other researchers. In oblique collisions, the profiles of the local Nusselt numbers are asymmetric. The locations of the peak Nusselt numbers do not coincide with the geometric center of the planar jet on the surface.
\end{abstract}

Keywords: convective heat transfer, planar water jet, oblique impingement, jet cooling 


\section{Introduction}

The impingement of free-surface liquid jets is widely utilized in various industrial processes, including curtain coating in paper industries [1], vehicle windshield deicing/defogging [2, 3], and draft cooling in the manufacture of liquid crystal sheets [4]. In steel manufacturing industries, impinging liquid jets are applied in hot rolling processes to cool hot metal plates [5-7]. There are two types of cooling methods, namely pipe cooling systems and curtain cooling systems. In the former method, hot materials are cooled by the impingement of an array of jets issuing from round nozzles. In contrast, the curtain cooling system employs planar impinging jets. Since steel products undergo several phase transformations during cooling and contain various phases, the metal structure of the finished products is strongly dependent on the cooling temperature history. Thus, accurate control of the temperature of the metal plates and their uniform cooling are needed to produce the desired mechanical characteristics. The utilization of planar jets is one method that satisfies these requirements.

Figure 1 shows a schematic diagram of a planar impinging jet. The liquid jet issues from a slot nozzle into the air, and then impinges on the solid surface. Film flow on the solid surface results from the impingement of the jet. The heat transfer characteristics of the interaction between the jet and the flat surface depend on the liquid flow rate and the impingement angle. There have been many studies of the heat transfer characteristics of a planar jet impinging normally on a flat surface in the range of high or moderate Reynolds numbers $\left(R e>10^{4}\right.$ ), as surveyed below. Only a few studies have addressed such heat transfer at low Reynolds numbers. Furthermore, studies of obliquely impinging jets are relatively rare, and a complete understanding of the heat transfer characteristics of planar water jets has not yet been achieved.

The objective of this study was to investigate the heat transfer characteristics of a planar water jet impinging normally or obliquely on a flat surface. In our experiments, the planar jet issued from a rectangular slot nozzle impinges on a flat surface under the conditions of constant heat-flux maintained with the Joule heating technique. The temperature of the solid surface was maintained below the boiling temperature of the liquid. The experiments were conducted in a low Reynolds number range $(R e<9000)$ to 
address the deficiency of experimental data for this region. The jet velocity and the impingement angle were varied systematically to investigate the effects of these parameters on the heat transfer characteristics. In this paper, we discuss these results, and a constitution equation for prediction of the heat transfer coefficient in the stagnation zone is proposed.

\section{Literature survey}

A brief survey of studies of the normal impingement of planar jets is now presented. Watson [8] analyzed the motion in the layer of a planar liquid jet impinging on a flat surface by applying the boundary-layer theory for laminar or turbulent flows. Miyazaki et al. [9] studied the heat transfer characteristics of a two-dimensional laminar jet impinging on a flat surface theoretically by assuming potential flows; the boundary-layer equations and the energy equation were solved with the finite difference method. Sparrow [10] analytically examined the flow and heat transfer characteristics of a planar jet with a fully developed velocity profile impinging on a flat surface. Chen et al. [11] investigated the heat transfer of a planar jet under arbitrary-heat-flux conditions theoretically. Caiesla et al. [12] and Beaubert et al. [13] computed the flow field of a planar impinging jet by using a large eddy simulation (LES) technique.

Miyasaka et al. [14] investigated the local heat transfer characteristics of a water planar jet impinging on a hot solid with a constant heat flux; the temperature and pressure were measured at several locations to determine the local heat transfer rate and the flow velocity across the boundary layer. A similar study at a lower Reynolds number ( $R e=940$ ) was conducted by Inada et al. [15]. Zumbrunnen et al. [16] empirically investigated the convective heat transfer distribution of a planar water jet impinging on a flat surface; measurements were carried out under transient conditions, and the results were obtained for both during and after the period of boundary layer growth on an initially dry surface. Vader et al. [17] examined the heat transfer distribution of a planar water jet impinging on a flat, constant heat-flux surface; the jet issued from a converging nozzle with a near-uniform velocity profile. Their experiments were 
conducted in the range of jet Reynolds number $2 \times 10^{4}<R e_{j}<9 \times 10^{4}$. Empirical formulae for heat transfer at the stagnation point were proposed. In a later study [18], convective nucleate boiling heat transfer from a flat, constant heat-flux surface to a planar water jet with a near-uniform velocity profile was investigated.

Wolf et al. [19] measured the local jet velocity of a planar water jet issued from a slot nozzle. The effect of a non-uniform velocity profile on local heat transfer was studied under the conditions of $1.7 \times 10^{4}<R e_{j}<7.9 \times 10^{4}$. In later studies [20, 21], they measured the local jet velocity and turbulence intensity of a planar water jet to investigate the local heat transfer characteristics of a jet impinging on a uniformly heated surface. Wolf et al. [22] further examined the effects of hydrodynamic conditions on the nucleate boiling heat transfer characteristics of a planar water jet. Webb et al. [23] have provided an excellent review of studies of axisymmetric and planar impinging jets.

Oblique impinging jets have also been studied. Tamada [24] provided an exact solution of the Navier-Stokes equations for two-dimensional steady stagnation-point flows impinging obliquely on a flat surface. Energy equation was not solved. Garg [25] analyzed theoretically the heat transfer characteristics of a two-dimensional laminar jet impinging obliquely on a flat plate by means of a finite difference technique; the effects of impingement angle on the velocity and temperature distributions were investigated. Tong [26] numerically analyzed the hydrodynamics and heat transfer characteristics of a planar liquid jet impinging obliquely on a flat surface; the influences of Reynolds number, impingement angle, and inlet velocity profile were studied. McMurray et al. [27] experimentally studied the local heat transfer characteristics of a planar water jet impinging obliquely on a flat surface, and proposed an empirical expression for the heat transfer in the stagnation and uniform parallel flow zones. Table 1 lists outlines of the abovementioned studies in order to clearly define the experimental conditions investigated in the present study. 


\section{Experimental apparatus}

\section{Set-up}

Figure 2 shows a schematic diagram of the experimental apparatus and the coordinate system used in the present study. Water supplied from a pump runs through a pipeline, a regulating valve, and a flow meter, and then flows into a reservoir composed of transparent acrylic plastic with an internal cross section of $40 \times 40 \mathrm{~mm}^{2}$ and a height of $250 \mathrm{~mm}$. The water passes through a $50 \mathrm{~mm}$ thick flow distributor filled with $5 \mathrm{~mm}$ diameter glass beads, followed by a $50 \mathrm{~mm}$ length of honeycomb with a cell diameter of $5 \mathrm{~mm}$, so that flow disturbance is minimized. A slot nozzle consisting of two parallel plates is located underneath the reservoir. The flow length of the slot nozzle is $75 \mathrm{~mm}$. The nozzle gap, $d_{0}$, between the two plates is $1.62 \mathrm{~mm}$ and the nozzle width, $l_{0}$, is 40.0 $\mathrm{mm}$.

The planar jet issues vertically downward from the slot nozzle and then impinges on an Inconel alloy heater plate that is $30 \mathrm{~mm}$ wide $(W), 100 \mathrm{~mm}$ long $(L)$, and $0.3 \mathrm{~mm}$ thick $(D)$, as shown in Fig. 3. Two $3 \mathrm{~mm}$ ends of the plate in the across-the-width direction are bent at a right angle to the plate. The Inconel plate is electrically heated with a DC power supply with a peak output of $3 \mathrm{~kW}$ (300 A at $10 \mathrm{~V}$ ). Seven pairs of K-type thermocouples with a wire diameter of $0.3 \mathrm{~mm}$ are spot-welded and firmly attached with small amount of heat-stable epoxy adhesive at $10 \mathrm{~mm}$ intervals along the center line of the opposite (non-wet) plate surface, as shown in Fig. 4. Each pair of thermocouple wires were set along the opposite plate surface in the across-the-width direction where the temperature gradient of the solid surface is small. A pair of copper probes were spot-welded with a separation of $80 \mathrm{~mm}$ on the reverse side of the plate to measure the difference between the voltages, $E$, at these points. The local temperatures, $T_{\mathrm{m}}$, on the reverse side of the plate as well as the difference between the voltages were measured with a data logger. The accuracy of measurement of the temperature was within plus or minus 0.1 degrees Celsius.

The heater plate is firmly attached to a $15 \mathrm{~mm}$ thick insulator, which has a thermal conductivity of $0.3 \mathrm{Wm}^{-1} \mathrm{~K}^{-1}$. The heater unit is set on a multi-axis precision positioning stage with a spatial resolution of $0.01 \mathrm{~mm}$ in the horizontal and vertical directions, and a 
tilt angle resolution of $0.1^{\circ}$. Thus, the nozzle-to-plate spacing, $H$, the impingement angle, $\alpha$, and the location of the impingement line of the planar jet can be adjusted with high precision. In this study, the nozzle-to-plate spacing, $H$, was set at $10.0 \mathrm{~mm}$. The origin of the coordinate system was set at the center of the impingement line of the planar jet, as shown in Fig. 2. The temperature distribution near the impingement line was measured with fine spatial resolution by slightly shifting the multi-axis stage in the $x$ direction.

Every cooling test was conducted under steady state conditions. During these experiments, the water flow rate was monitored with the flow meter and maintained at a preset value by adjusting the regulating valve. The volume flow rate of water, $Q$, was measured directly from the volume of water discharged from the nozzle exit during a period of 60 seconds. The mean vertical velocity at the nozzle exit, $V_{0}$, was evaluated from the flow rate, $Q$, and the cross-sectional area, $d_{0} l_{0}$, of the nozzle exit. The mean velocities at the nozzle exit examined in this study were 1.5, 2.1, 2.6, 3.9, 5.1, and 6.1 $\mathrm{ms}^{-1}$. The corresponding Reynolds numbers are 2200, 3000, 3700, 5700, 7400, and 8800, respectively, and are defined as,

$$
R e=\frac{V_{0} d_{0}}{v}
$$

where $v$ is the kinematic viscosity coefficient of the water. The corrected velocity, $V$, and width, $d$, are also defined as follows, taking account of gravity,

$$
\begin{aligned}
& V=\left(V_{0}^{2}+2 g H\right)^{1 / 2} \\
& d=\frac{V_{0} d_{0}}{V}
\end{aligned}
$$

where $g$ is the gravitational acceleration. The jet Reynolds number is defined by

$$
R e_{j}=\frac{V d}{v_{0}}
$$

where the kinematic viscosity coefficient, $v_{0}$, can be evaluated from the film temperature, $\left(T_{f}+T_{w}\right) / 2 ; T_{f}$ and $T_{w}$ are the water and wall temperatures respectively. The water temperature, $T_{f}$, ranges from 16 to $22^{\circ} \mathrm{C}$. In addition, the heat flux was fixed 
at $0.28 \mathrm{MWm}^{-2}$ in all cases.

\section{Data reduction}

The temperature distribution of the solid surface on which the planar jet impinges was computed using the temperature profiles for the reverse surface of the plate and the rate of heat generation due to Joule heating. The heat conduction equation inside the heater plate in the two-dimensional coordinate system is given by,

$$
\lambda_{p}\left(\frac{\partial^{2} T}{\partial x^{2}}+\frac{\partial^{2} T}{\partial y^{2}}\right)+\dot{q}=0
$$

where $(x, y)$ are the coordinates shown in Fig. 5 and $\lambda_{p}$ and $\dot{q}$ are the thermal conductivity of the Inconel plate $\left(=10.1 \mathrm{Wm}^{-1} \mathrm{~K}^{-1}\right)$ and the rate of heat generation per unit volume, respectively.

Equation (5) can be solved with the finite-volume technique proposed by Vader et al. [28]. The rectangular computer domain is divided into $1000 \times 50$ cells in the $x$ and $y$ directions. The heat loss at the opposite surface through the insulator is assumed to be negligibly small. The condition at the southern boundary is

$$
\left.\frac{\partial T}{\partial y}\right|_{\text {South }}=0 \text {. }
$$

As the number of temperature measurement points on the opposite surface is fewer than the number of computational cells in the $x$ direction, a simple linear interpolation of the measured temperatures was employed to determine the temperature at the boundary.

At the eastern and western boundaries of the computational domain, the temperature gradients in the $x$ direction were assumed to be very small:

$$
\left.\frac{\partial T}{\partial x}\right|_{\text {East }}=0,\left.\quad \frac{\partial T}{\partial x}\right|_{\text {West }}=0 .
$$

The local heat transfer coefficient, $h$, can be determined from Newton's law of cooling,

$$
h=\frac{q}{T_{w}-T_{f}} .
$$

The local Nusselt number, $\mathrm{Nu}$, is defined as, 


$$
N u=\frac{h d_{0}}{\lambda_{f}}=\frac{q d_{0}}{\left(T_{w}-T_{f}\right) \lambda_{f}}
$$

where $\lambda_{f}$ is the thermal conductivity of the water. In addition, the jet Nusselt number at the stagnation line is given by,

$$
N u_{j}=\frac{h d}{\lambda_{f 0}}
$$

where the thermal conductivity, $\lambda_{f 0}$, can be evaluated from the film temperature, $\left(T_{f}\right.$ $\left.+T_{w}\right) / 2$.

\section{Results and discussion}

\section{Normal impingement}

Figure 6(a) depicts the distributions of the surface temperature of the heated plate in the $x$ direction for $V=1.6,2.1,2.6,4.0,5.1$, and $6.1 \mathrm{~m} / \mathrm{s}$ and normal impingement ( $\alpha=90^{\circ}$ ). The corresponding jet Reynolds numbers are 2600, 3400, 4200, 6100, 8300, and 9400, respectively. The surface temperature is lowest at the impingement line and increases with departures from it. The distribution of the surface temperature is bilaterally-symmetric with respect to the impingement line, suggesting that the flow structure in this set-up is symmetric. The surface temperature decreases with increases in the mean jet velocity. Figures 6(b) and 6(c) show the distributions of the corresponding local heat transfer coefficient and the Nusselt number respectively. The peak values of the heat transfer coefficient and the Nusselt number arise at the impingement line, decrease outward, and also increase with increases in the mean jet velocity.

A simple flow model that assumes a two-dimensional, steady and laminar flow was considered, as shown in Figure 7. When the vertical planar jet impinges normal to the horizontal plate, the thickness of the film formed along the solid surface is approximately half of the jet width. Very thin hydrodynamic and thermal boundary layers are formed in the stagnation zone and develop outward. The hydrodynamic boundary layers are thicker than the thermal boundary layers because of $\operatorname{Pr}>1$. The 
free-stream velocity, $U_{\infty}$, and free-stream temperature, $T_{\infty}$, outside the boundary layer are nearly identical to the jet velocity, $V$, and temperature, $T_{f}$, respectively. The temperature at the solid surface is low in the stagnation region and increases outward. As a consequence, the peak values of the heat transfer coefficient and the Nusselt number arise at the impingement point.

The similarity solutions for two-dimensional, steady, and laminar impinging flows without a free liquid surface are well known [29]. The exact solution of the local Nusselt number is given for Falkner-Skan flows [30, 31] in the Prandtl number range $0.7<\operatorname{Pr}<10$ by

$$
\frac{N u_{x}}{R e_{x}^{0.5}}=0.569 \operatorname{Pr}^{0.376}
$$

where $N u_{x}$ and $R e_{x}$ are the local Nusselt and Reynolds numbers given by

$$
N u_{x}=\frac{h x}{\lambda_{f 0}} \text { and } R e_{x}=\frac{U_{\infty} x}{v_{0}} .
$$

In the stagnation zone, potential theory shows that the local free-stream velocity is given by $U_{\infty}=C x$, where $C$ is the streamwise velocity gradient, $d U_{\infty} / d x$. The stagnation zone free-stream velocity gradient for a planar jet with a uniform velocity profile can be expressed as [32],

$$
C=\frac{d U_{\infty}}{d x}=\frac{\pi}{4} \frac{V}{d} .
$$

Substituting Eq. (13) into Eq. (11), we obtain,

$$
N u_{j}=0.505 \operatorname{Re}_{j}^{0.5} \operatorname{Pr}^{0.376} \text {. }
$$

Tong [26] conducted 2-D numerical simulations of a planar liquid jet impinging on a hot solid. The numerical results for a uniform jet velocity profile are in good agreement with Eq. (14), even though the presence of a free surface is not taken into account by Eq. (14). He also demonstrated that the stagnation Nusselt number is strongly dependent on the jet velocity profile. In the case of a parabolic jet velocity profile, the calculated stagnation Nusselt number is appreciably larger than indicated by Eq. (14).

As shown in Figure 8, the predictions of Eq. (14) are approximately 25\% less than the experimental values. This discrepancy between the results of the present experiments 
and those of Eq. (14) is thought to be due to the non-uniform velocity profile. The jet velocity is small near the free surface and large at the jet center. Since the flow length of the slot nozzle used in the present experiments is insufficiently long to yield a fully developed laminar flow, the velocity profile cannot be estimated correctly at the nozzle exit. In addition, Vader et al. [17] have reported that Nusselt numbers obtained with Eq. (14) are 30-50\% less than their experimental data.

Correlations for predicting the stagnation Nusselt numbers have been proposed for large Reynolds numbers (Vader et al. [17]; Wolf et al. [19, 21]; McMurray et al. [27]). Vader et al. [17] proposed the following correlation:

$$
N u_{j}=0.28 \operatorname{Re}_{j}^{0.58} \operatorname{Pr}^{0.4} \text {. }
$$

Their experiments were conducted under the conditions $2 \times 10^{4}<R e_{j}<9 \times 10^{4}$ and 2.7 $<\operatorname{Pr}<4.5$. The velocity profile of the jet was near-uniform. Wolf et al. [19] proposed the following correlation for the stagnation Nusselt number applicable to non-uniform velocity profiles:

$$
N u_{j}=0.116 \operatorname{Re}_{j}^{0.71} \operatorname{Pr}^{0.4} .
$$

The experimental conditions were $1.7 \times 10^{4}<R e_{j}<7.9 \times 10^{4}$ and $2.8<\operatorname{Pr}<5.0$ and the jets were turbulence flows. In their later study [21], a correlation for the stagnation Nusselt number was proposed in the following form:

$$
N u_{j}=0.202 \operatorname{Re}_{j}^{0.620} \operatorname{Pr}^{0.4} \text {. }
$$

The coefficient 0.202 and the exponent 0.620 were determined with a least-square method from their experimental data under the conditions that the Reynolds numbers are 23000 and 46000. It can be seen in Figure 8 that the predictions of Eqs. (15-17) do not agree with the present experimental data, which is probably because of differences between the flow structures in the stagnation region.

Inada et al. [15] studied the local heat transfer coefficients for Falkner-Skan flows. A normal impinging jet is a special case of Falkner-Skan flow. In their model, the flow field resulting from the impingement of a two-dimensional water jet on a flat surface is divided into two regions. The first region is an impingement zone and the other is a uniform parallel flow zone. The correlation for the stagnation Nusselt number is identical to Eq. (14). In the parallel flow zone, they used the following equation in the 
range $0.7<\operatorname{Pr}<10$,

$$
\begin{aligned}
\frac{N u}{\sqrt{R e}}= & 0.757(\beta+0.2)^{0.1}\left[(2-\beta)^{0.615+0.07 \beta}-0.26(2-\beta)\right] \\
& \times \operatorname{Pr}^{0.34+0.036 \beta} \frac{1}{\sqrt{2-\beta}} \sqrt{\frac{U_{\infty} / V_{0}}{x / d_{0}}}
\end{aligned}
$$

where $\beta$ is a parameter related to the velocity distribution at the outer edge of the boundary layer that depends on $x$. Figure 9(a) shows the local Nusselt numbers obtained from our experimental results and the predictions of Eq. (18) for various Reynolds numbers. The experimental data are in fair agreement with Eq. (18) in the region $x / d_{0}>$ 5 for $R e_{j}=4200$ and 2600, whereas agreement is poor at a high Reynolds number of $R e_{j}$ $=9400$.

Chen et al. [11] conducted a theoretical analysis to predict the heat transfer characteristics of a planar, free-surface, laminar impinging jet. In their model, the thermal and hydrodynamic boundary layers of the laminar flow were divided into four zones, namely a stagnation zone and three wall jet zones. The correlation for the stagnation Nusselt number can be expressed in the following form,

$$
N u_{j}=0.634 \operatorname{Re}_{j}^{0.5} \operatorname{Pr}^{0.38} \quad 3<\operatorname{Pr}<10 .
$$

For the wall jet zone, the local Nusselt numbers are given by

$$
N u_{j}=0.5136\left(\frac{d_{0}}{x}\right)^{0.24} \operatorname{Re}_{j}^{0.5} \operatorname{Pr}^{0.38} .
$$

It can be seen in Figure 8 that Eq. (19) satisfactorily describes the experiments in the stagnation zone. However, the Nusselt numbers predicted by Eq. (20) do not coincide with the experimental results outside the stagnation region, as shown in Figure 9(b). One source of this discrepancy is the assumptions of the model; their model assumes that the velocity profile in the velocity boundary layer is given by a classical polynomial function, which does not adequately describe actual flows.

In the region $x / d_{0}>5$, a similar trend to that found with Eq. (18) can be seen. Good agreement between this equation and the experimental data was found for low Reynolds numbers, whereas the predicted Nusselt numbers are underestimated for moderately high Reynolds numbers. Note that Eq. (20) provides better agreement with the 
experimental data than Eq. (18).

According to the similarity solutions for Falkner-Skan flows [29], the laminar boundary layer thickness, $\delta$, is given by

$$
\delta=2.4 \sqrt{v x / U_{\infty}} .
$$

The boundary layer thickness increases monotonically with $x$. At $x / d_{0}=20$, the calculated ( $\delta / d_{0}$ ) by Eq.(21) is 0.1 for $\operatorname{Re}_{j}=9400$ and 0.21 for $\operatorname{Re}_{j}=2600$, respectively, suggesting that the mainstream region is always present outside the boundary layers in $-20<x / d_{0}<20$. Chens' model [11] also gives similar results. A possible source for the discrepancy between the present experiments and the predictions of Eqs. (18) and (20) in the parallel flow region is the occurrence of transition from laminar to turbulent flow. In the cases of parallel flows over a flat plate, the flow transition occurs at $\operatorname{Re}_{\mathrm{X}} \sim 5 \times 10^{5}$, which is called critical Reynolds number [29]. Figure 9(c) represents the relation between $\operatorname{Re}_{\mathrm{x}}$ and the local Nusselt numbers. Although the critical Reynolds numbers for the plate boundary flows are not directly applicable to the present cases, the entire range of $\mathrm{Re}_{\mathrm{x}}$ seems in the laminar boundary flow regime where no flow transition occurs.

As shown in Figure 1, the planar jet is comprised of two rims with a center sheet in between (see also Fig. 1). The rims are rounded and thick because of surface tension. The retraction of the edges of the liquid film is more appreciable for a larger distance away from the nozzle exit. The surface tension also generates capillary (instability) waves. In the present experiments, the rims do not impinge on the heater plate to ensure 2-dimensional flows by setting a small nozzle-to-plate spacing $(H=10 \mathrm{~mm})$, but the formation of capillary waves is unavoidable. Also, the flow fluctuations caused by the experimental setup are not negligible at higher Reynolds numbers. As a consequence, the free liquid surface shows slight wavy motion, which promotes the mass and momentum transport in the film thickness direction. This mechanism is possibly the reason why the measured Nusselt numbers are larger than the theoretical predictions. 


\section{Oblique impingement}

Figure 10 depicts the distributions of the local Nusselt numbers in the $x$ direction for an impingement angle of $60^{\circ}$. The jet velocities vary with the parameter $V_{0}(2.6,3.1,3.6$, 4.1 and $4.6 \mathrm{~m} / \mathrm{s}$ ). The local Nusselt numbers decrease with increases in the impinging velocity associated with the jet Reynolds number. As expected, the $\mathrm{Nu}$ profiles are asymmetric. The Nusselt numbers on the downhill side $(x>0)$ are larger than those on the uphill side $(x<0)$ for the range $x / d_{0}>10$.

According to a simple potential flow theory [33], the liquid film thicknesses are $0.5 d(1-\cos \alpha)$ on the uphill side and $0.5 d(1+\cos \alpha)$ on the downhill side, i.e., the thickness of the liquid on the uphill side is less than that on the downhill side. The volume of liquid flowing downhill along the solid is larger than that flowing uphill. As a consequence, the stagnation point associated with the point of bifurcation of the uphill and downhill flows is shifted slightly uphill from the origin of the coordinates at which the geometric center of the jet on the solid surface is located. At the stagnation point, the hydrodynamic boundary layer is very thin. The thermal boundary layer thickness is also small, resulting in large local Nusselt numbers. This flow structure gives rise to asymmetric $\mathrm{Nu}$ profiles and the shift of the positions of the peak Nusselt number (see also Figs. 11 and 12). In addition, it is considered that the hydrodynamic boundary layer thickness at the stagnation point is thinner for larger jet Reynolds numbers, like normal impingements. It follows that the peak Nusselt number is dependent on the jet Reynolds number.

Figures 11(a) and 11(b) show the distributions of the Nusselt numbers in the $x$ direction for $V_{0}=2.1$ and $2.6 \mathrm{~m} / \mathrm{s}$ (the corresponding jet Reynolds numbers are 3400 and 4300 respectively). The impingement angles vary with the parameter $\alpha(90,70,60$, and $50^{\circ}$ ). On the uphill side, the Nusselt numbers decrease slightly with decreases in the impingement angle. On the downhill side, however, the effects of the impingement angle on the Nusselt numbers are not significant.

The observation that the local Nusselt numbers depend slightly on the impingement angle on the uphill side can be explained in terms of the thickness of mainstream, $\delta_{m}$ as defined in Figure 7. The thickness of mainstream on the uphill side is smaller than that 
on the downhill side in oblique collisions, although the distributions of $\delta_{m}$ cannot be given quantitatively. The mainstream region disappears not far from the stagnation point on the uphill side. The trends become appreciable for smaller impingement angle and/or smaller velocity. In addition, the slight wavy motion of free liquid surface, as mentioned above, affects the boundary layer structure in small $\delta_{m}$ regions. Hence, the Nusselt numbers on the downhill side are very similar regardless of the impingement angle, but depend on the impingement angle on the uphill side.

Figures 12(a) and 12(b) show the distributions of the local Nusselt numbers in the stagnation zone. For an angle of $50^{\circ}$, the peak Nusselt number is significantly smaller than in the other cases. The positions of the peak Nusselt numbers shift towards the uphill side. The shifting distance is at most $d_{0}$ (nozzle gap). Tong [26] conducted two-dimensional simulations of the hydrodynamics and heat transfer characteristics of a planar liquid jet impinging obliquely on a flat surface, and the profiles of the local Nusselt numbers in the stagnation zone were studied in detail. He reported that the shift in the peak Nusselt number increases with decreases in the impingement angle. The similar trends can be obtained in the present experiments. According to a potential flow theory [34], the stagnation point moves uphill as $\alpha$ decreases: the shifting distance given by the theory is $0.52 d$ for $\alpha=70^{\circ}$, and $0.96 d$ for $\alpha=50^{\circ}$, respectively. Thus, the shift in the peak Nusselt number is quite natural. Tong [26] also showed that the shifting distance of the peak Nusselt number from $x=0$ is larger than the shift of the stagnation point. In the figure, the positions of the peak Nusselt number for $\alpha=50^{\circ}$ look located slightly uphill to the predicted stagnation point by the potential flow theory [34] ( $x / d$ ${ }_{0}=0.96$ ), but the spatial resolution of the temperature measurement is not fine enough to discuss the phenomena.

Beitelmal et al. [35] investigated the effects of the inclination of an impinging two-dimensional air jet on the heat transfer from a uniformly heated flat plate. They also reported that the displacement of the maximum heat transfer point is at most $1.5 d_{0}$ from the geometrical impinging point, although their experimental conditions are very different from the conditions of this study.

McMurray [27] proposed correlations for predicting the local Nusselt numbers in 
the stagnation and uniform parallel flow zones for a planar, free-surface, water jet. Correlations were defined for both laminar and turbulent flows as a function of the impingement angle, the Prandtl number, and the jet Reynolds number. In the cases of laminar boundary layers, the following correlation was proposed,

$$
\left.N u_{j}\right|_{\alpha} /\left.N u_{j}\right|_{\alpha=0^{\circ}}=1+0.63 \sin (\alpha / 0.85)
$$

where $\left.N u_{j}\right|_{\alpha=0^{\circ}}$ is the Nusselt number for $\alpha=0^{\circ}$ (parallel flow over a flat plate). It should be noted that Eq. (22) was obtained empirically and do not have maximum values at $\alpha=90^{\circ}$. As $\left.N u_{j}\right|_{\alpha=0^{\circ}}$ cannot be measured in the present set-up, a direct comparison of these equations with the results of our experiments is impossible. Instead, we propose the following correlations with a similar functional form for predicting the maximum Nusselt number:

$$
N u_{j}=0.395\{1+0.63 \sin (\alpha / 0.85)\} \operatorname{Re}_{j}^{0.5} \operatorname{Pr}^{0.38}
$$

Equation (23) is identical to Eq. (19) if $\alpha=90^{\circ}$. Figures 13 compare the results of Eq.(23) with the present experimental data. There is reasonable agreement between Eq.(23) and the present experimental data.

\section{Conclusions}

The heat transfer of a planar water jet impinging normally or obliquely on a heated surface was investigated. The effects of the jet velocity and the impingement angle on the heat transfer characteristics were examined. The main results obtained in this study are summarized below.

(1) In the case of normal collisions, the peak value of the Nusselt number arises at the impingement line and decreases with departures from it; it also increases with increase of the mean jet velocity. The stagnation and local Nusselt numbers are in reasonable agreement with the correlation in Eq. (19).

(2) In the case of oblique collisions, the profiles of the local Nusselt numbers are asymmetric. The position with the peak Nusselt number shifts uphill for small impingement angles. The local Nusselt numbers on the uphill side decrease with 
decreases in the impingement angle. In contrast, on the downhill side the effects of the impingement angle on the Nusselt numbers are not significant. Further, a correlation for predicting the peak Nusselt numbers was proposed, which is given in Eq. (23).

\section{References}

[1] H. Alleborn, PROGRESS IN COATING THEORY, Thermal Science, 5 (1) (2001) 131-152.

[2] S. Roy, K. Nasr, P. Patel and B. AbdulNour, An experimental and numerical study of heat transfer off an inclined surface subject to an impinging airflow, International Journal of Heat and Mass Transfer 45 (8) (2002) 1615-1629.

[3] S. Roy and P. Patel, Study of heat transfer for a pair of rectangular jets impinging on an inclined surface, International Journal of Heat and Mass Transfer 46 (3) (2003) 411-425.

[4] H. Serizawa, T. Yanagida and T. Kuboyama, Distribution of Heat Transfer Coefficients of an Impinging Two Dimensional Free Jet on an Oblique Flat Surface, Transactions of the Japan Society of Mechanical Engineers. B, 66 (650) (2000) 2669-2674 (in Japanese).

[5] S.-J. Chen and A.A. Tseng, Spray and jet cooling in steel rolling, International Journal of Heat and Fluid Flow, 13 (4) (1992) 358-369.

[6] N. Hatta, Y. Tanaka, H. Takuda and J. Kokado, A Numerical Study on Cooling Process of Hot Steel Plates by a Water Curtain, ISIJ International, 29 (8) (1989) 673-679.

[7] N. Hatta, and H. Osakabe, Numerical Modeling for Cooling Process of a Moving Hot Plate by a Laminar Water Curtain, ISIJ International, 29 (11) (1989) 919-925.

[8] E.J. Watson, The radial spread of a liquid jet over a horizontal plane, Journal of Fluid Mechanics, 20 (3) (1964) 481-499.

[9] H. Miyazaki and E. Silberman, Flow and heat transfer on a flat plate normal to a 
two-dimensional laminar jet issuing from a nozzle of finite height, International Journal of Heat and Mass Transfer, 15 (11) (1972) 2097-2107.

[10] E.M. Sparrow and L. Lee, Analysis of flow field and impingement heat/mass transfer due to nonuniform slot jet, ASME Journal of Heat Transfer, 97 (1975) 191-197.

[11] Y.C. Chen, C.F. Ma, M. Qin and Y.X. Li, Theoretical study on impingement heat transfer with single-phase free-surface slot jets, International Journal of Heat and Mass Transfer, 48 (2005) 3381-3386.

[12] T. Cziesla, G. Biswas, H. Chattopadhyay and N. K. Mitra, Large-eddy simulation of flow and heat transfer in an impinging slot jet, International Journal of Heat and Fluid Flow, 22 (5) (2001) 500-508.

[13] F. Beaubert and S. Viazzo, Large eddy simulations of plane turbulent impinging jets at moderate Reynolds numbers, International Journal of Heat and Fluid Flow, 24 (2003) 512-519.

[14] Y. Miyasaka and S. Inada, The effect of pure forced convection on the boiling heat transfer between a two-dimensional subcooled water jet and a heated surface, Journal of Chemical Engineering of Japan, 13 (1) (1980) 22-28.

[15] S. Inada, Y. Miyasaka and R. Izumi, A study of the laminar flow heat transfer between a two-dimensional water jet and a flat surface with constant heat flux, Bulletin of the JSME, 24 (1981) 1803-1810.

[16] D.A. Zumbrunnen, F.P. Incropera and R. Viskanta, Convective heat transfer distributions on a plate cooled by planar water jets, ASME Journal of Heat Transfer, 111 (1989) 889-896.

[17] D.T. Vader, F.P. Incropera and R. Viskanta, Local convective heat transfer from a heated surface to an impinging, planar jet of water, International Journal of Heat and Mass Transfer, 34 (3) (1991) 611-623.

[18] D.T. Vader, F.P. Incropera and R. Viskanta, Convective nucleate boiling on a heated surface cooled by an impinging, planar jet of water, ASME Journal of Heat Transfer, 114 (1992) 152-160.

[19] D.H. Wolf, R. Viskanta and F.P. Incropera, Local convective heat transfer from a 
heated surface to a planar jet of water with a nonuniform velocity profile, ASME Journal of Heat Transfer, 112 (1990) 899-905.

[20] D.H. Wolf, R. Viskanta and F.P. Incropera, Turbulence Dissipation in a Free-Surface Jet of Water and Its Effect on Local Impingement Heat Transfer From a Heated Surface Part 1-Flow Structure, ASME Journal of Heat Transfer, 117 (1995) 85-94.

[21] D.H. Wolf, R. Viskanta and F.P. Incropera, Turbulence Dissipation in a Free-Surface Jet of Water and Its Effect on Local Impingement Heat Transfer From a Heated Surface Part 2-Local Heat Transfer, ASME Journal of Heat Transfer, 117 (1995) 95-103.

[22] D.H. Wolf, F.P. Incropera and R. Viskanta, Local jet impingement boiling heat transfer, International Journal of Heat and Mass Transfer, 39 (7) (1996) 1395-1406.

[23] B.W. Webb and C.-F. Ma, Single-phase liquid jet impingement heat transfer, Advances in Heat Transfer, 26 (1995) 105-217.

[24] K. Tamada, Two-Dimensional Stagnation-Point Flow Impinging Obliquely on a Plane Wall, Journal of the Physical Society of Japan, 46 (1) (1979) 310-311.

[25] V.K. Garg and S. Jayaraj, Boundary layer analysis for two-dimensional slot jet impingement on inclined plates, ASME Journal of Heat Transfer, 110 (1988) 577-582.

[26] A.Y. Tong, On the impingement heat transfer of an oblique free surface plane jet, International Journal of Heat and Mass Transfer, 46 (2003) 2077-2085.

[27] D.C. McMurray, P.S. Myers and O.A. Uyehara, Influence of impinging jet variables on local heat transfer coefficients along a flat surface with constant heat flux, Proceedings 3rd International Heat Transfer Conference, AIChE, New York, 2 (1966) 292-299.

[28] D.T. Vader, F.P. Incropera and R. Viskanta, A method for measuring steady local heat transfer to an impinging liquid jet, Experimental Thermal and Fluid Science, 4 (1) (1991) 1-11.

[29] L.C. Burmeister, CONVECTIVE HEAT TRANSFER, 2nd ed., J. Wiley, New York, 1993, pp.186-196. 
[30] H.L. Evans, Mass transfer through laminar boundary layers - further similar solutions to the $B$-equation for the case $B=0$, International Journal of Heat and Mass Transfer, 5 (1962) 35-57.

[31] S. Levy, Heat transfer to constant-property laminar boundary layer flows with power-function free-stream velocity and wall-temperature variation, Journal of Aeronautical Sciences, 19 (1952) 341-348.

[32] L.M. Milne-Thomson, Theoretical Hydrodynamics, 3rd ed., Macmillan, New York, 1955, pp.279-289

[33] G.K. Batchelor, An Introduction to Fluid Dynamics, Cambridge University Press., 1967, p.393.

[34] W.Schach, Umlenkung eines freien Flussigkeitsstrahles an einer ebenen Platte, Ing. Arch. 5(1934) 245-265.

[35] A.H. Beitelmal, M.A. Saad and C.D. Patel, The effect of inclination on the heat transfer between a flat surface and an impinging two-dimensional air jet, International Journal of Heat and Fluid Flow, 21 (2000) 156-163.

\section{List of Figure and Table Captions}

Figure 1 : Schematic diagram of a planar jet impinging on a solid surface.

Figure 2 : Schematic diagram of the experimental apparatus and the definitions of the coordinates.

Figure 3 : Schematic diagram of the experimental apparatus (the Inconel plate and the insulator).

Figure 4 : Positions of the thermocouples and voltage probes.

Figure 5 : Schematic diagram of the thermal model used in data reduction.

Figure 6 : Effects of the mean jet velocity on the heat transfer.

Figure 7 : Schematic diagram of a normally impinging jet and the boundary layer.

Figure 8 : Correlations for the stagnation Nusselt number for normal impingement.

Figure 9 : The experimental and predicted local Nusselt numbers.

Figure 10 : Effects of the mean jet velocity on the local Nusselt numbers for oblique 
impingements $\left(\alpha=60^{\circ}\right)$.

Figure 11 : Effects of the impingement angle on the Nusselt number profiles.

Figure 12 : Effects of the impingement angle on the Nusselt numbers located near the impingement point.

Figure 13 : Correlation of the predicted maximum Nusselt number with the experimental maximum Nusselt number for normal/oblique impingement.

Table 1 : Summary of the literature survey.

\section{Nomenclature}

C streamwise velocity gradient, $d U_{\infty} / d x$

$c_{f} \quad$ specific heat of water, $\mathrm{Jg}^{-1} \mathrm{~K}^{-1}$

D thickness of the Inconel plate, $\mathrm{m}$

D thickness of the planar water jet at the impingement point, $\mathrm{m}$

$d_{0} \quad$ nozzle thickness, $\mathrm{m}$

E voltage drop, $\mathrm{V}$

G dimensionless streamwise velocity gradient, $d\left(U_{\infty} / V\right) / d(x / d)$

G acceleration due to gravity, $\mathrm{ms}^{-2}$

$H \quad$ nozzle-to-plate spacing, $\mathrm{m}$

$H \quad$ heat transfer coefficient, $\mathrm{Wm}^{-2} \mathrm{~K}^{-1}$

$I_{\alpha} \quad$ mean Nusselt number

L $\quad$ plate length, $\mathrm{m}$

$l_{0} \quad$ nozzle width, $\mathrm{m}$

$\mathrm{Nu} \quad$ Nusselt number, $h d_{0} / \lambda_{f}$

$N u_{j} \quad$ jet Nusselt number, $h d / \lambda_{f 0}$

$N u_{x} \quad$ local Nusselt number, $h x / \lambda_{f 0}$

$\operatorname{Pr} \quad$ Prandtl number, $\mu c_{f} / \lambda_{f}$

Q volume flow rate of water, $\mathrm{m}^{3} \mathrm{~s}^{-1}$ 
heat-flux at the solid surface, $\mathrm{Wm}^{-2}$

rate of heat generation, $\mathrm{Wm}^{-3}$

Re Reynolds number, $V_{0} d_{0} / v$

$R e_{j}$

jet Reynolds number, $V_{0} d / v_{0}$

$R e_{x}$

local Reynolds number, $V_{0} X / v_{0}$

T

temperature, ${ }^{\circ} \mathrm{C}$

$T_{f}$

fluid temperature at the nozzle exit, ${ }^{\circ} \mathrm{C}$

$T_{\text {film }}$

film temperature, $\left(T_{w}+T_{f}\right) / 2$, ${ }^{\circ} \mathrm{C}$

$T_{m}$

temperature at the opposite (non-wet) face of the plate, ${ }^{\circ} \mathrm{C}$

$T_{w}$

solid surface temperature, ${ }^{\circ} \mathrm{C}$

$T_{\infty}$

free-stream temperature, ${ }^{\circ} \mathrm{C}$

$U_{\infty}$

free-stream velocity, $\mathrm{ms}^{-1}$

$u, v$

local flow velocities in the $x$-, $y$ - directions, $\mathrm{ms}^{-1}$

V

mean vertical jet velocity at the impingement point, $\mathrm{ms}^{-1}$

$V_{0}$

mean vertical jet velocity at the nozzle exit, $\mathrm{ms}^{-1}$

W

plate width, $\mathrm{m}$

$x_{c}$

streamwise location where the thermal boundary layer reaches the free surface

\section{Greek Symbols}

$\alpha$

impingement angle with respect to the solid surface, ${ }^{\circ}$

$\Delta x$

distance between the peak position of the Nusselt number and the geometrical impingement point, $\mathrm{m}$

$\delta \quad$ thickness of the hydrodynamic boundary layer, m

$\delta_{m} \quad$ thickness of the mainstream, m

$\delta_{T} \quad$ thickness of the thermal boundary layer, $\mathrm{m}$

$\lambda_{f} \quad$ thermal conductivity of water at the jet temperature, $\mathrm{Wm}^{-1} \mathrm{~K}^{-1}$

$\lambda_{f 0} \quad$ thermal conductivity of water at the film temperature, $\mathrm{Wm}^{-1} \mathrm{~K}^{-1}$ 
$\lambda_{p} \quad$ thermal conductivity of the plate, $\mathrm{Wm}^{-1} \mathrm{~K}^{-1}$

$\mu$

dynamic viscosity of water, Pa.s

$v$

kinetic viscosity of water at the jet temperature, $\mathrm{m}^{2} \mathrm{~s}^{-1}$

$v_{0}$

kinetic viscosity of water at the film temperature, $\mathrm{m}^{2} \mathrm{~s}^{-1}$ 


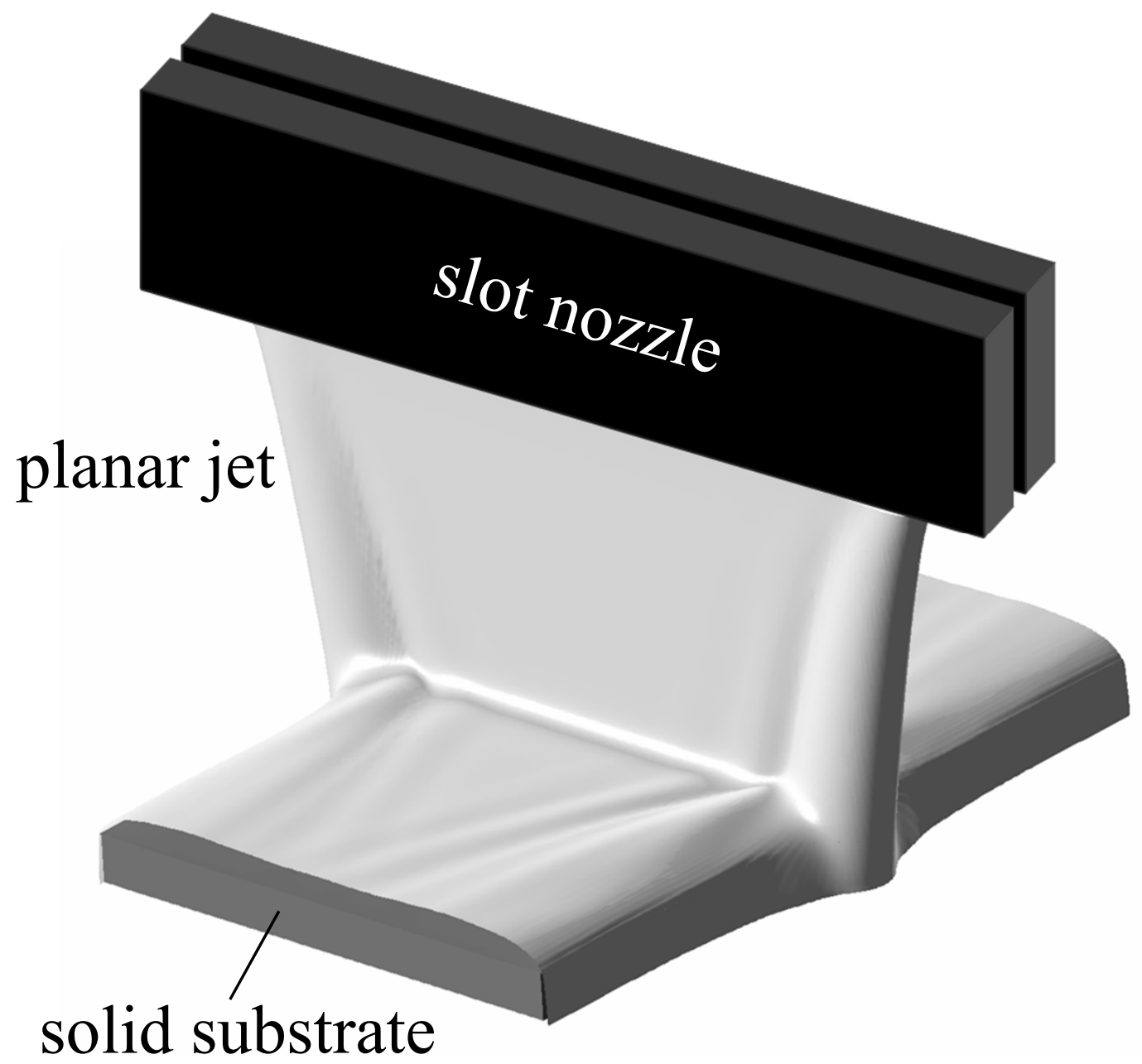

Fig. 1 Schematic diagram of a planar jet impinging on a solid surface 


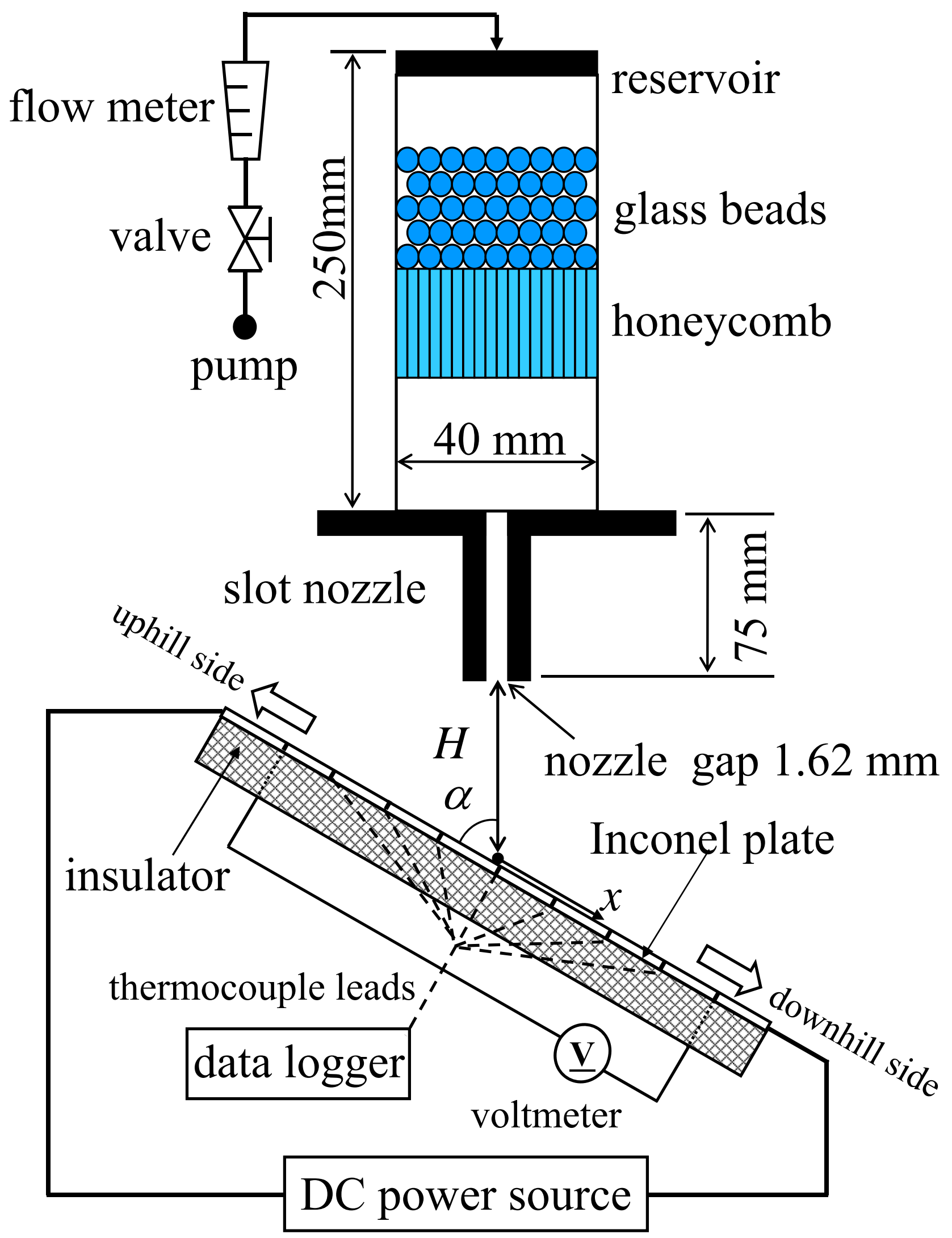

Fig. 2 Schematic diagram of the experimental apparatus and the definition of the coordinates 


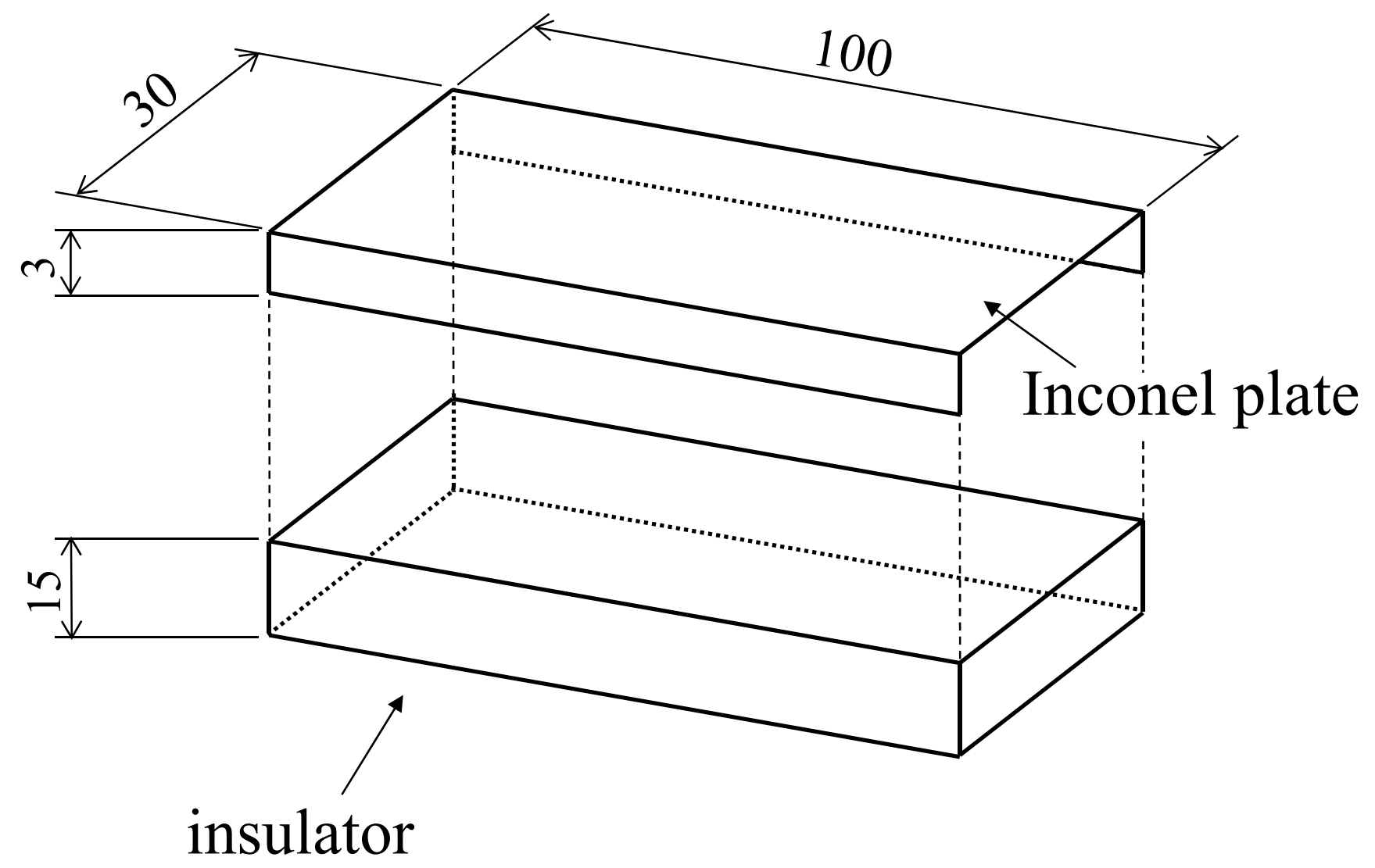

unit $\mathrm{mm}$

Fig. 3 Schematic diagram of the experimental apparatus (the Inconel plate and the insulator) 


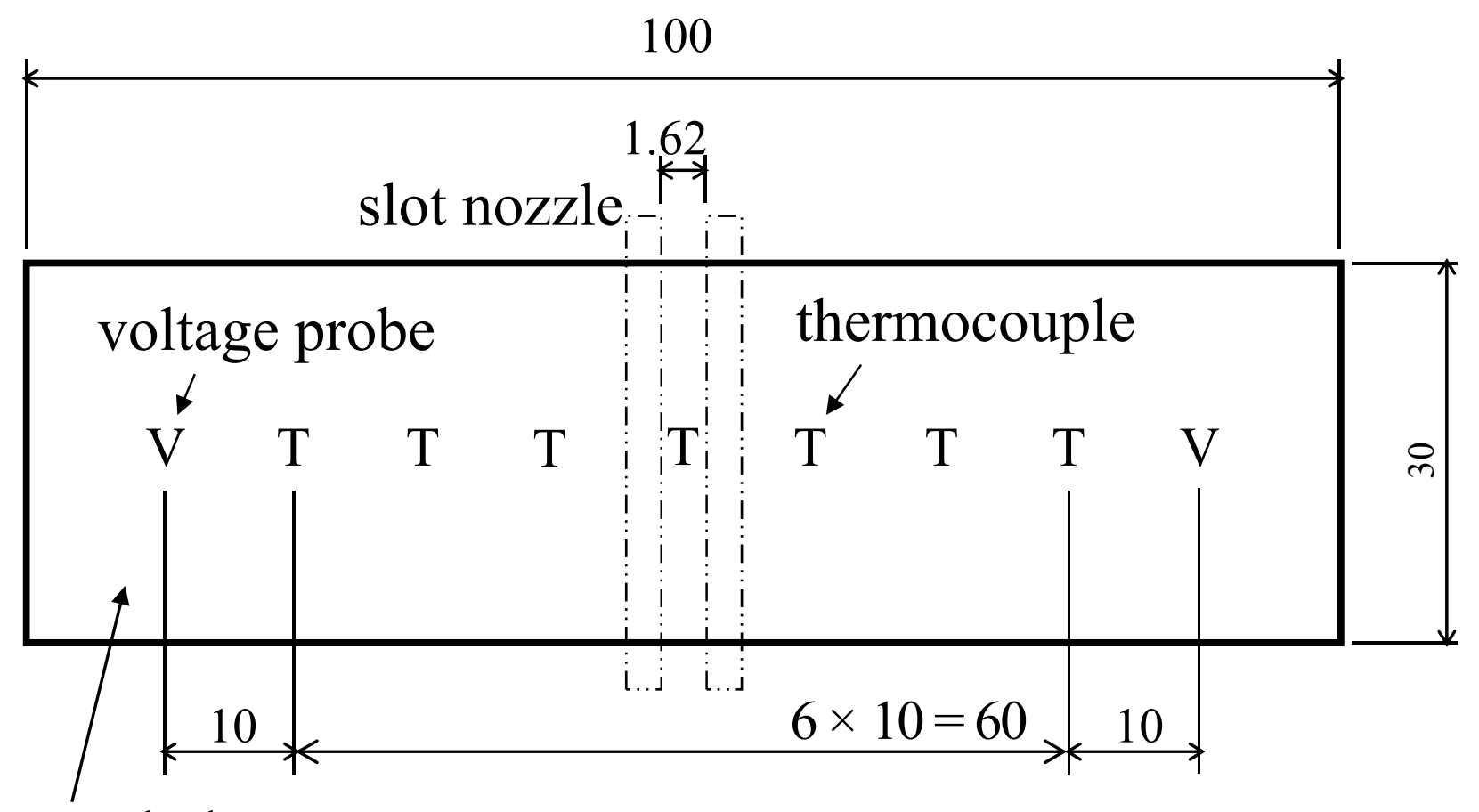

Inconel plate

unit $\mathrm{mm}$



Fig. 4 Positions of the thermocouples and voltage probes 


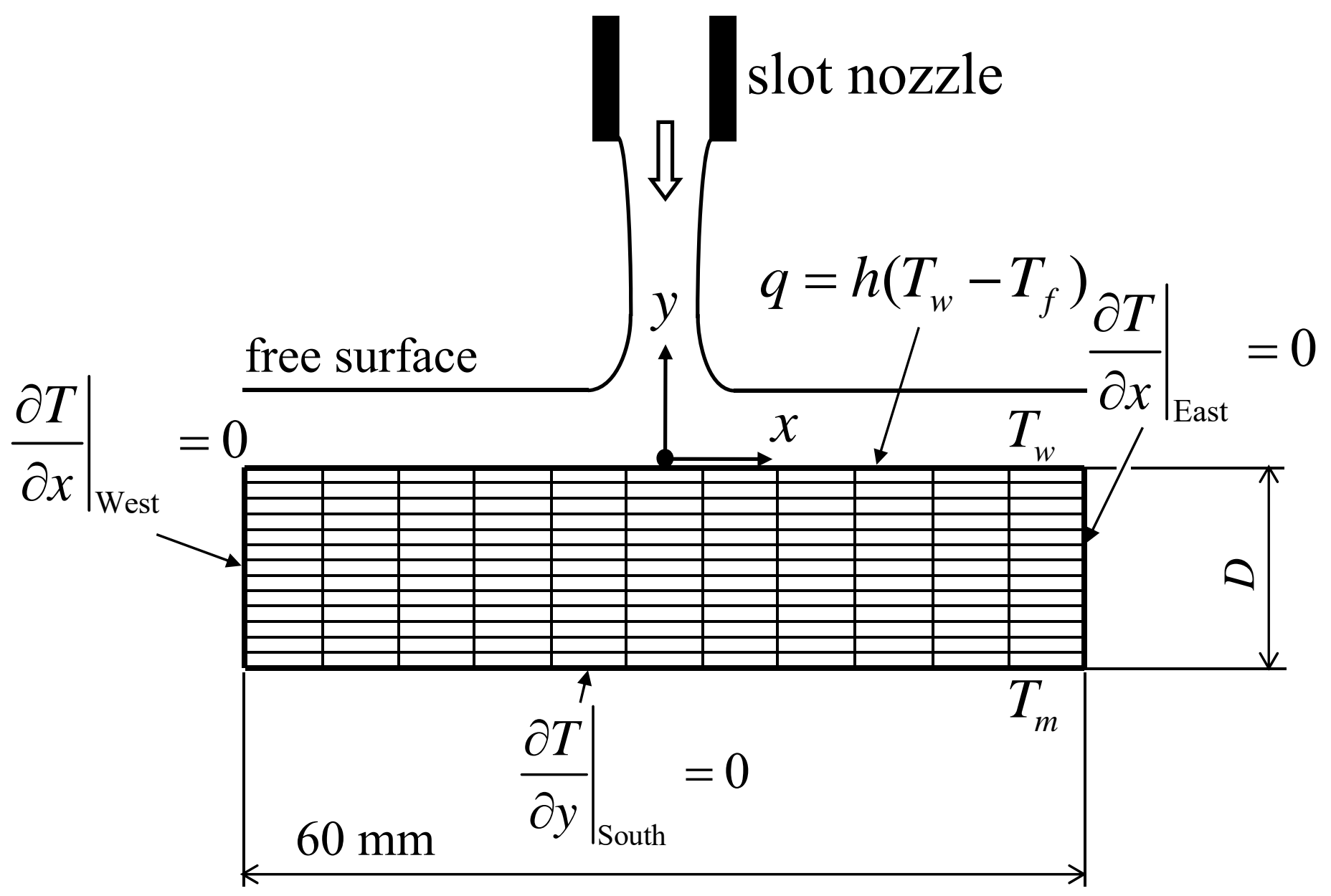

Fig. 5 Schematic diagram of the thermal model used in data reduction 

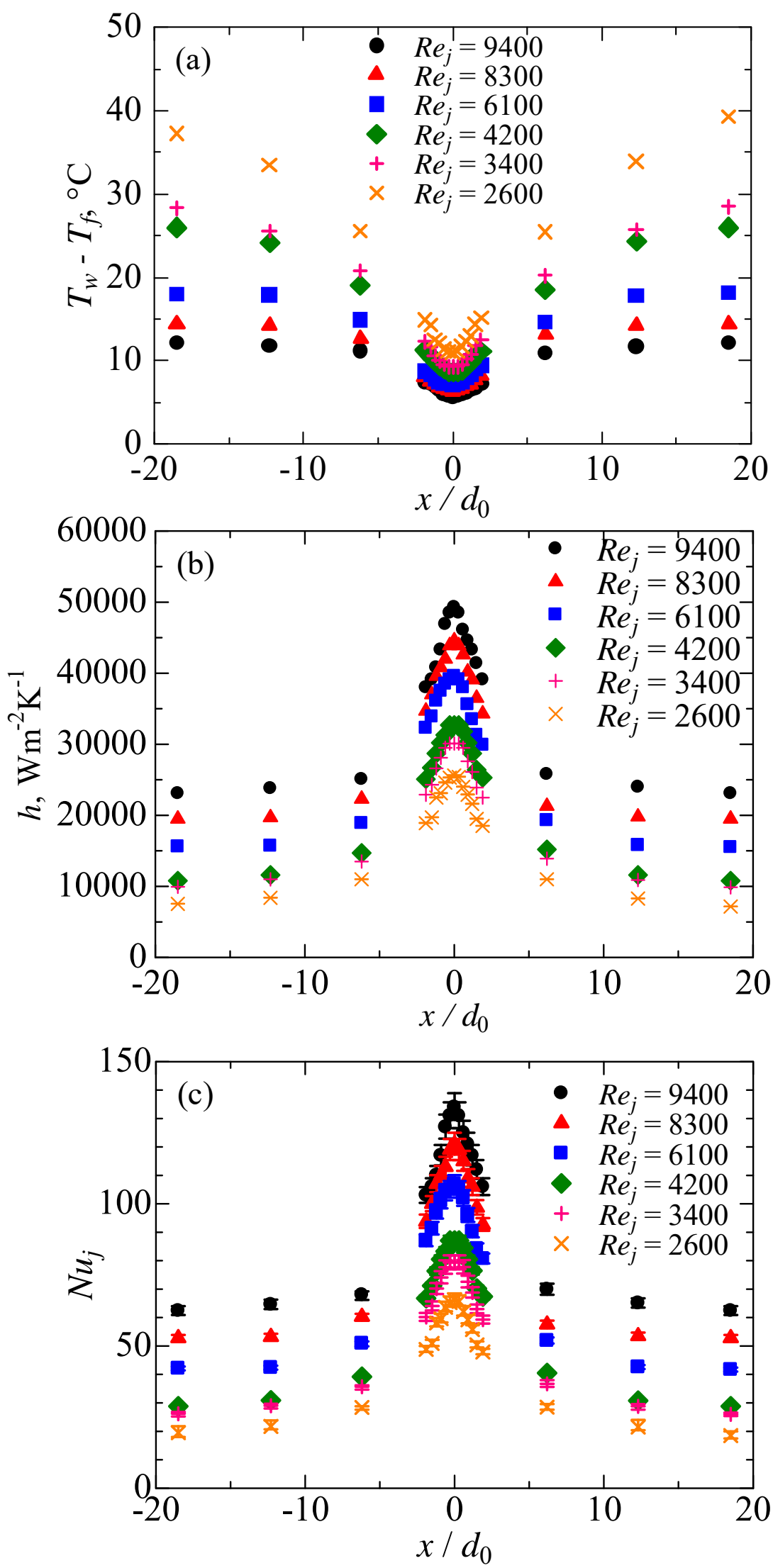

Fig. 6 Effects of the mean jet velocity on the heat transfer. 


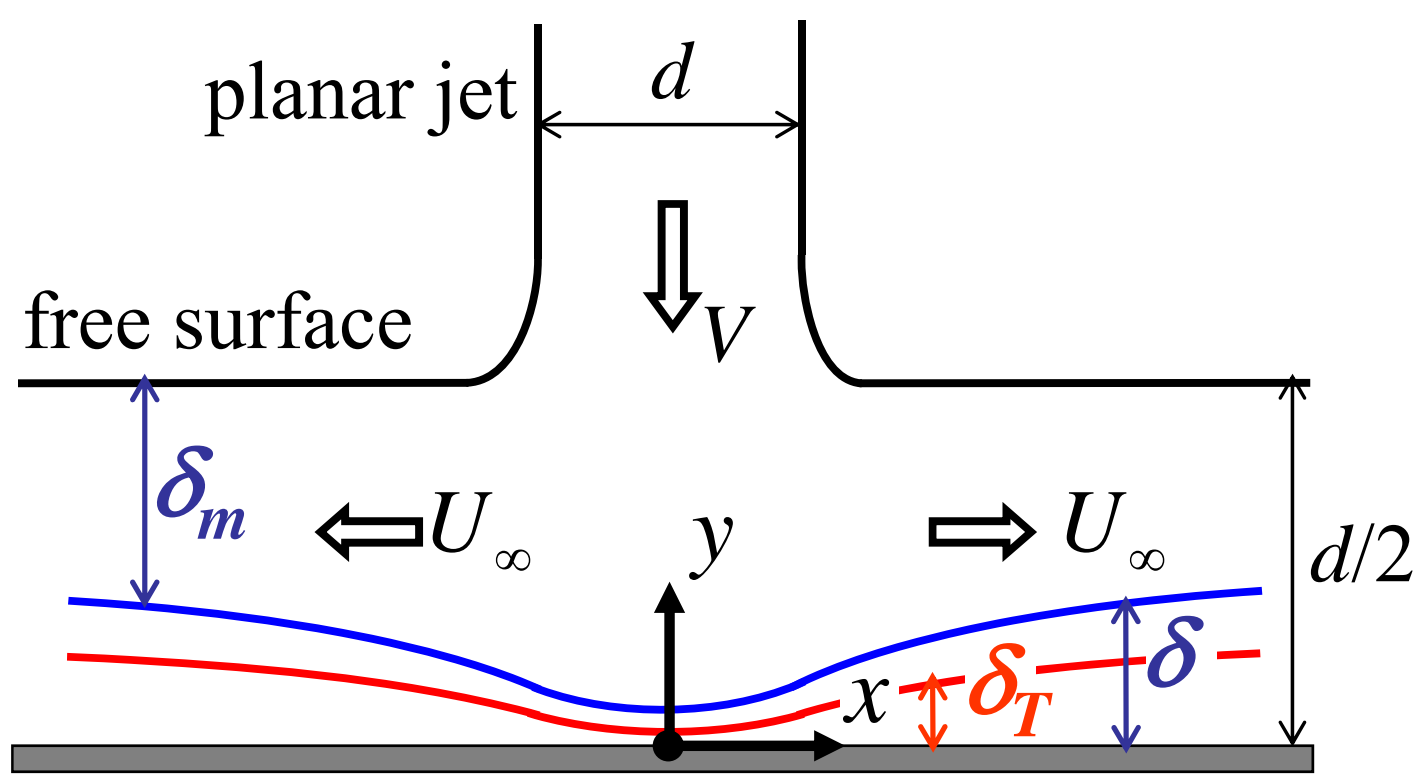
parallel flow zone $\begin{gathered}\text { stagnation } \\ \text { zone }\end{gathered} \longrightarrow$ parallel flow zone

Fig. 7 Schematic diagram of a normally impinging jet and the boundary layer 


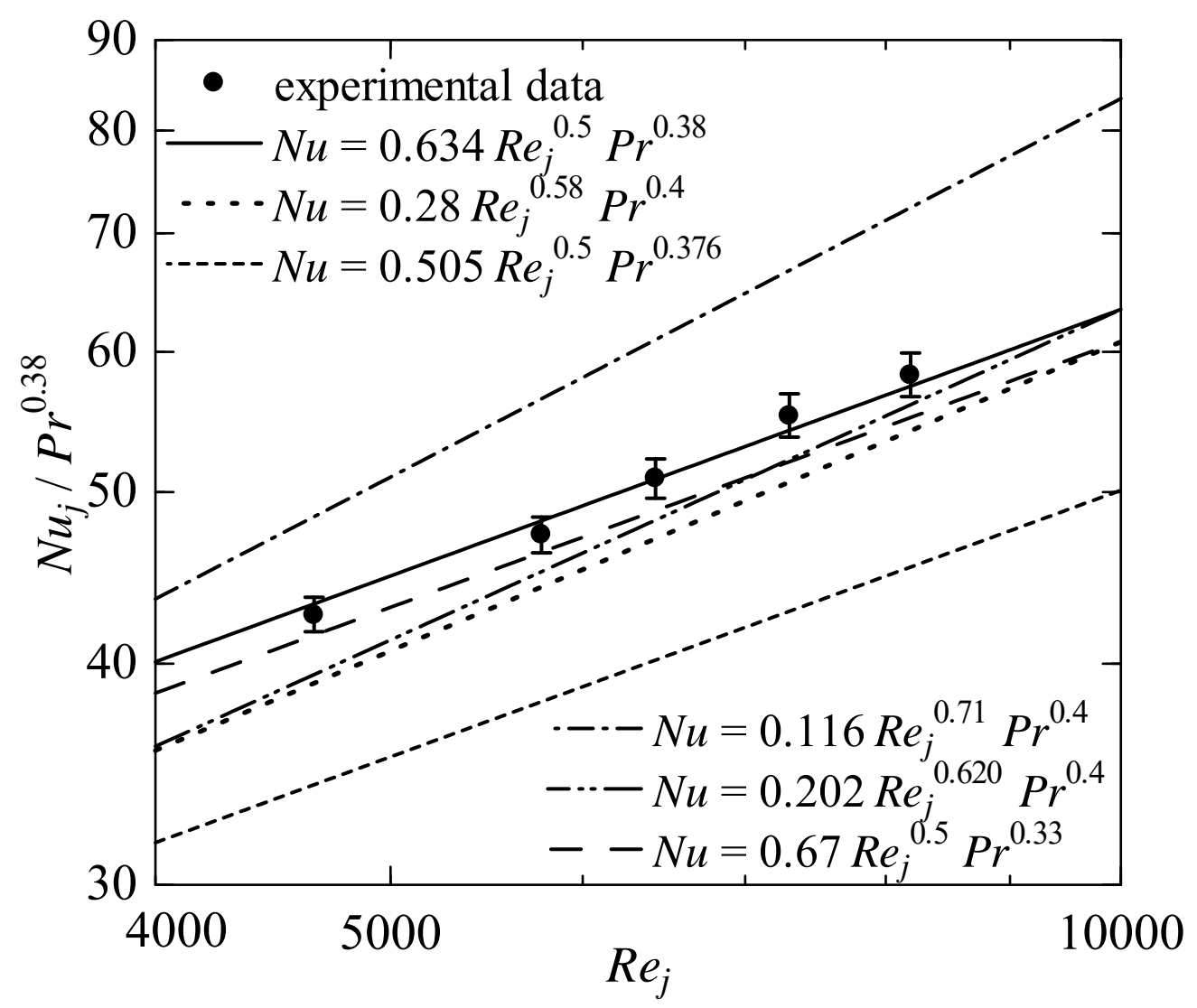

Fig. 8 Correlations for the stagnation Nusselt number for normal impingement 



Fig. 9 The experimental and predicted local Nusselt numbers. 




Fig. 10 Effects of the mean jet velocity on the local Nusselt numbers for oblique impingements $\left(\alpha=60^{\circ}\right)$. 

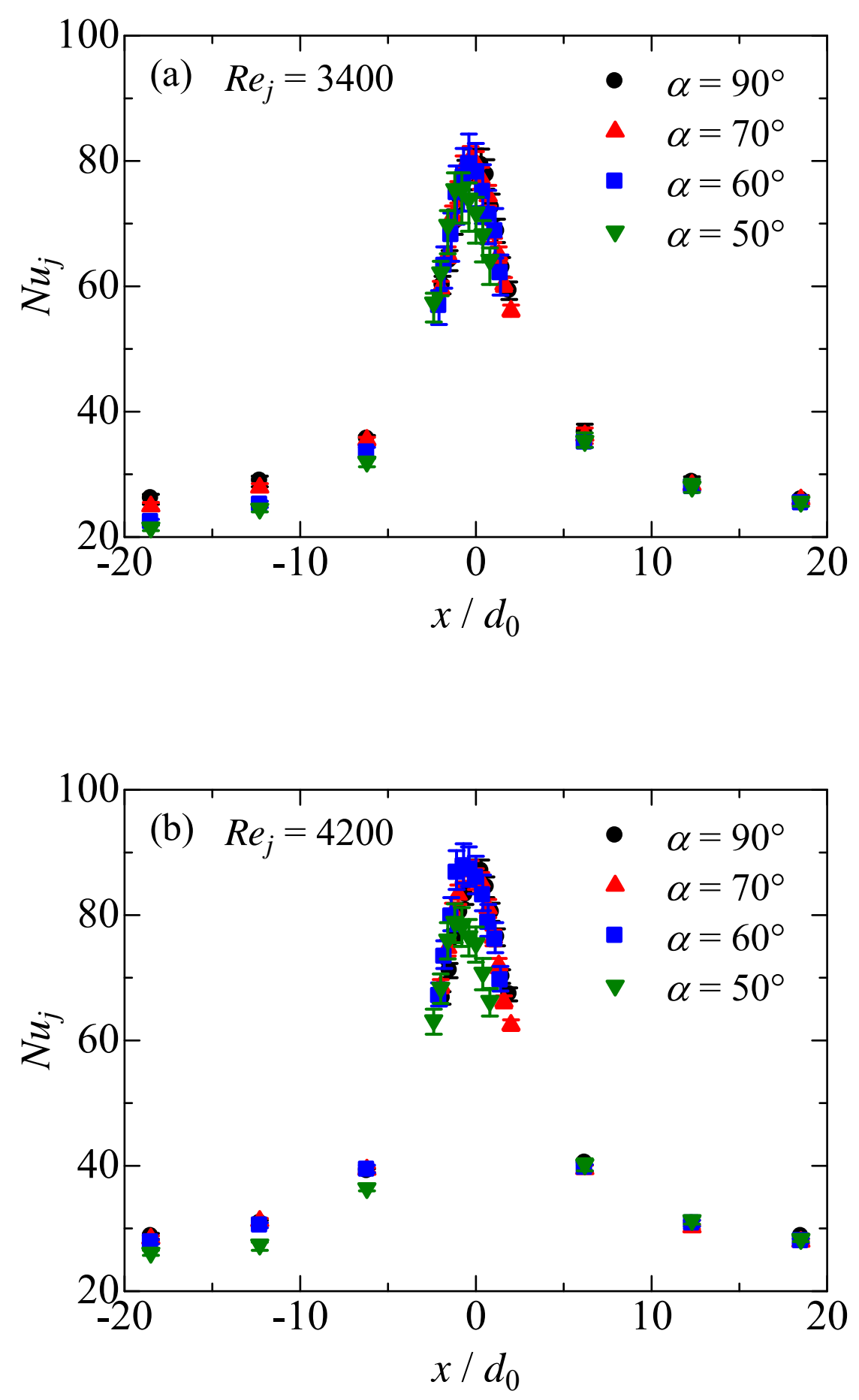

Fig. 11 Effects of the impingement angle on the Nusselt number profiles 

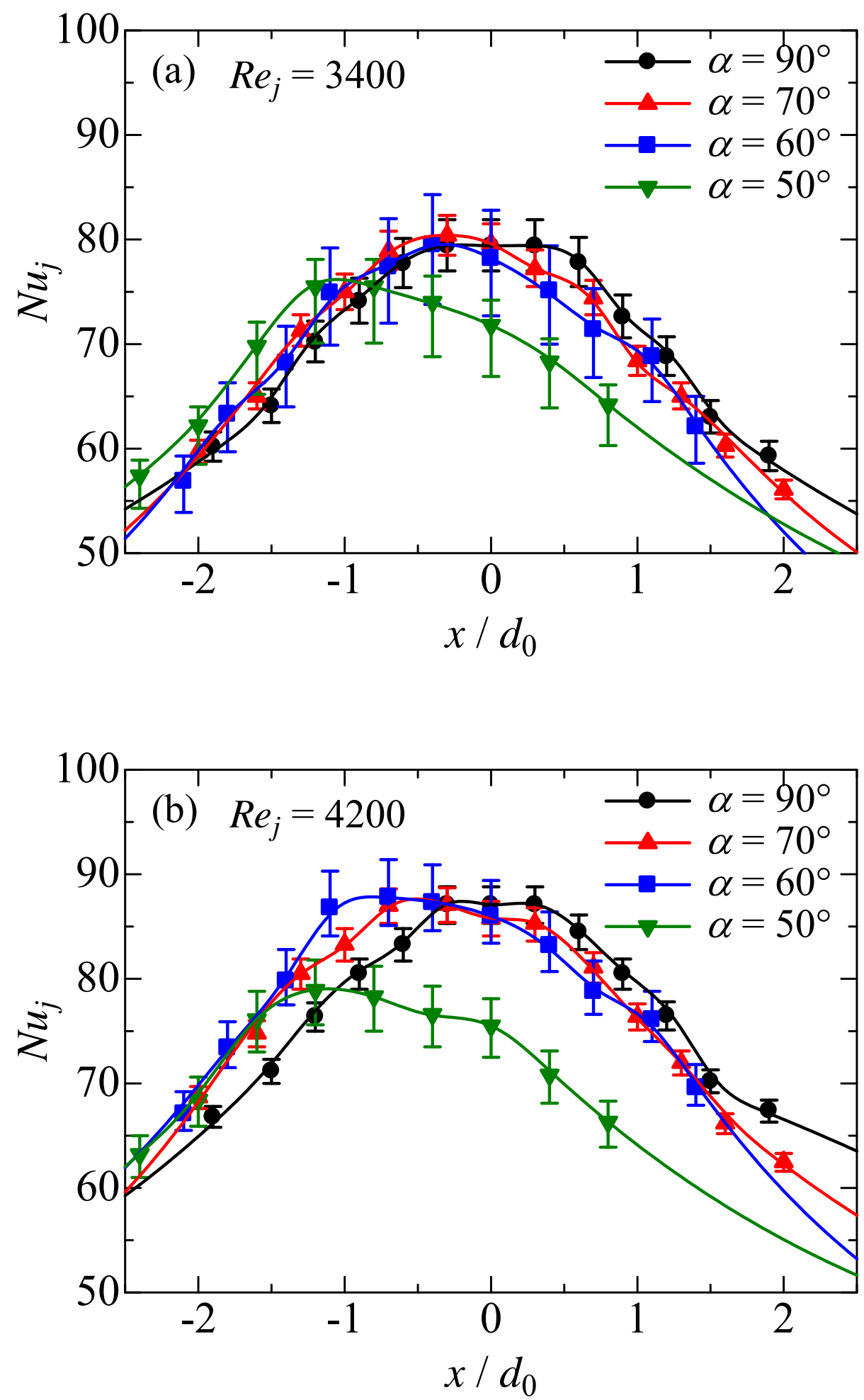

Fig. 12 Effects of the impingement angle on the Nusselt numbers located near the impingement point. 


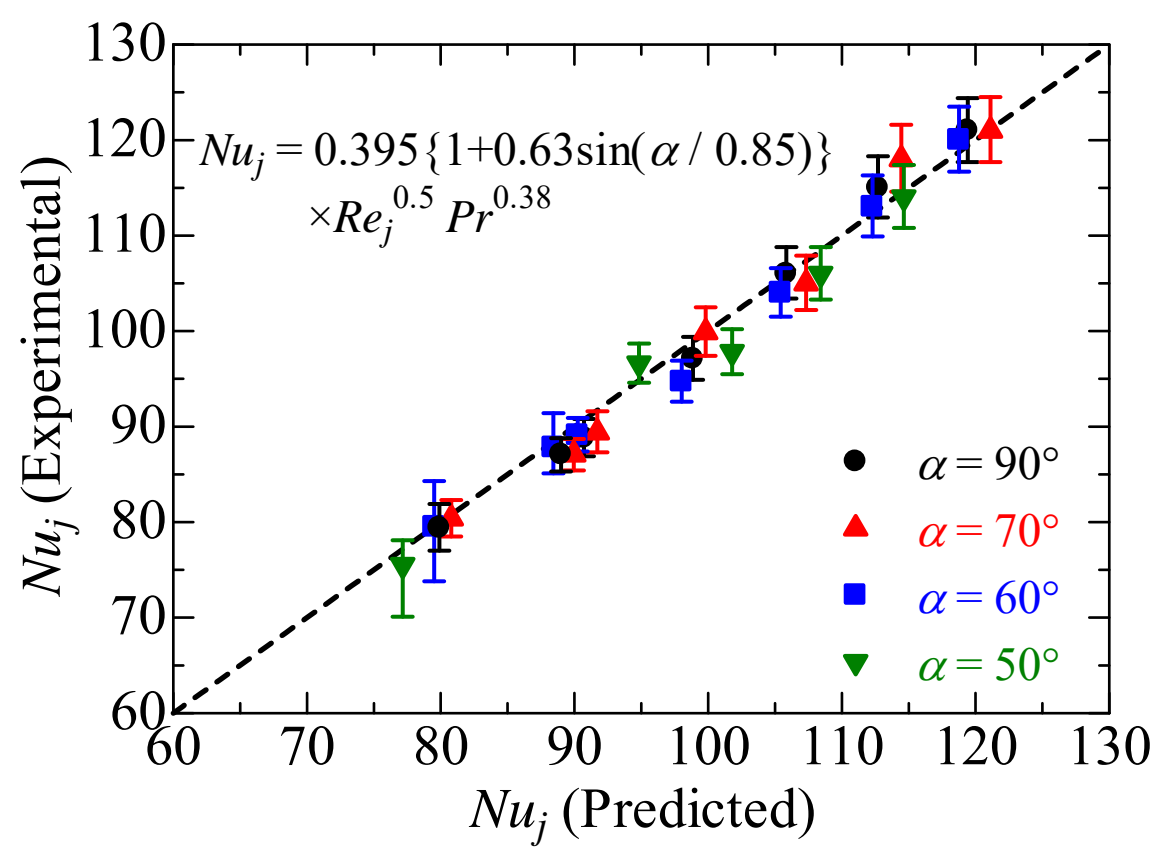

Fig. 13 Correlation of the predicted maximum Nusselt number with experimental maximum Nusselt number for normal/oblique impingement 
Table 1. Summary of the literature survey

\begin{tabular}{ccccc}
\hline Literature & $\begin{array}{c}\text { Theory/experiment/ } \\
\text { computation }\end{array}$ & $\begin{array}{c}\text { Normal/ } \\
\text { oblique } \\
\text { impingement }\end{array}$ & Reynolds number & Boiling \\
\hline Chen et al. [11] & theory & normal & no \\
Miyasaka and Inada [14] & experiment & normal & $10,500<R e j<157,000$ & yes \\
Inada et al. [15] & theory, experiment & normal & $940(R e)$ & no \\
Zumbrunnen et al. [16] & experiment & normal & $11,700<R e j<86,800$ & no \\
Vader et al. [17] & experiment & normal & $15,500<R e<46,200$ & no \\
Vader et al. [18] & experiment & normal & $15,500<R e<46,200$ & yes \\
Wolf et al. [19] & experiment & normal & $15,000<R e<54,000$ & yes \\
Wolf et al. [20, 21] & experiment & normal & 23,000 and $46,000(R e)$ & no \\
Wolf et al. [22] & experiment & normal & 23,000 and $46,000(R e)$ & yes \\
Garg [25] & computation & oblique & & no \\
Tong [26] & computation & oblique & 2,500 and $10,000(R e)$ & no \\
McMurray [27] & experiment & oblique & $69,000<R e j<137,000$ & no \\
this study & experiment & normal/oblique & $2,200<R e<8,800$ & no \\
\hline
\end{tabular}

